\title{
The effect of green-coffee-bean extract rich in chlorogenic acid on antioxidant status of healthy human volunteers
}

\author{
S. Almoosawi, C. Tsang, I. Davidson, L. Fyfe and E. A. S Al-Dujaili \\ Department of Dietetics, Nutrition and Biological Sciences, Queen Margaret University, Queen Margaret Drive, \\ Musselburgh EH21 6UU, UK
}

Several studies have linked consumption of green-coffee-bean extract (GCBE) rich in chlorogenic acid (CGA) with reduced blood pressure $^{(1-3)}$. It is hypothesised that increased antioxidant activity could be one of the underlying mechanisms by which GCBE reduces blood pressure. To test this hypothesis a GCBE preparation rich in CGA was assessed by three extraction methods for antioxidant activity. In vivo antioxidant activity was also determined in a group of healthy volunteers.

The phenolic content of GCBE, as determined by the Folin-Ciocalteu method, varied greatly between the ethanolic acidified water $(0.2 \%(\mathrm{v} / \mathrm{v})$ formic acid) and acetonitrile extract (acetonitrile-water containing $0.2 \%(\mathrm{v} / \mathrm{v})$ formic acid; $50: 50, \mathrm{v} / \mathrm{v}): 123(\mathrm{SD} 0.23), 131$ (SD 0.66) and 211 (SD 0.51) $\mathrm{mg}$ gallic acid equivalents (GAE)/g extract respectively. Similar findings were observed with the $\mathrm{Fe}^{3+}$ reducing ability of plasma (FRAP) assay, wherein the acetonitrile extract exhibited a stronger $\mathrm{Fe}^{3+}$-reducing ability than the ethanolic extract $(0.067 \mathrm{mmol} / \mathrm{g}$ extract $v .0 .048 \mathrm{mmol} / \mathrm{g}$ extract). The 2,2-di(4-tert-octylphenyl)-1-picrylhydrazyl (DPPH) radical-scavenging activity of the ethanolic extract of GCBE was $70.4 \%$ at $50 \mu \mathrm{M}$ as compared with ascorbic acid $(86.1 \%$ inhibition at $50 \mu \mathrm{M})$ and GAE $(82.2 \%$ at $50 \mu \mathrm{M})$.

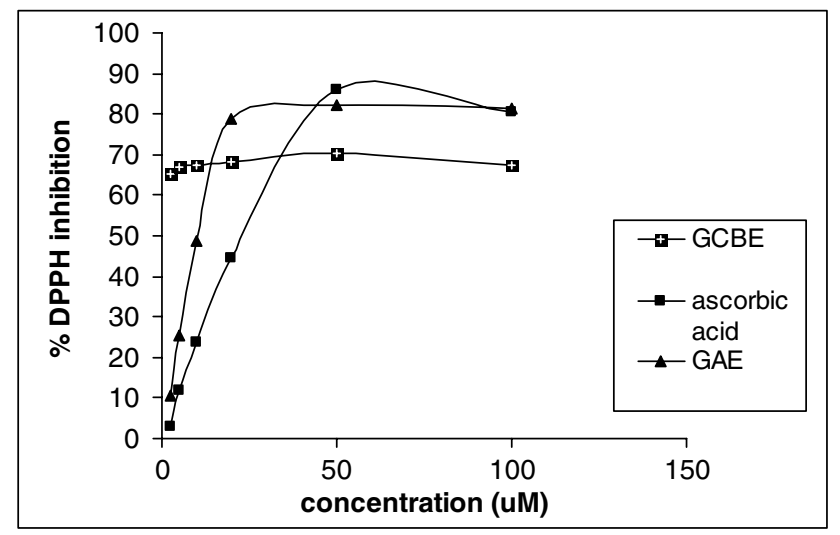

To examine in vivo antioxidant properties of GCBE thirteen healthy volunteers (age 36 (SD 11) years, BMI 28 (SD 2.5 ) $\mathrm{kg} / \mathrm{m}^{2}$ ) consumed $200 \mathrm{mg}$ GCBE containing $90 \mathrm{mg}$ CGA twice daily for 2 weeks. In vivo antioxidant activity was determined using the Folin-Ciocalteu method and FRAP. There was a significant correlation between urinary polyphenols excretion as determined by the Folin-Ciocalteu method and FRAP $(0.664, P<0.0001)$. However no significant increase in urinary antioxidant activity was observed (total phenolics: 173.2 (SD 137.8) $\mathrm{mg} \mathrm{GAE} / \mathrm{g}$ creatinine $v$. 175.20 (SD 115.7) $\mathrm{mg}$ GAE/g creatinine, $P>0.05$; FRAP: 2.07 (SD 0.9 ) $\mathrm{mmol} \mathrm{Fe}^{2+} / \mathrm{g} \mathrm{creatinine} v$. 1.56 (SD 0.7) $\mathrm{mmol} \mathrm{Fe} \mathrm{Fe}^{2+} / \mathrm{g}$ creatinine, $P>0.05$ ). Systolic blood pressure decreased from 119 (SD 10.5) to $114(\mathrm{SD} 9.1) \mathrm{mmHg}(P=0.05)$ following the 2-week treatment.

In conclusion, green coffee bean extract has a high antioxidant activity. However, no changes in antioxidant activity are observed in urine. This finding is consistent with previous findings of poor antioxidant activity of hippuric acid, the main urinary metabolite of chlorogenic acid ${ }^{(4)}$. Further research is required to identify the mechanism(s) of reduction in blood pressure. The antioxidant activity of plasma should also be determined.

1. Watanabe T, Arai Y, Mitsui Y et al. (2006) Clin Exp Hypertens 28, 439-449.

2. Kozuma K, Tsuchiya S, Kohori J et al. (2005) Hypertens Res 28, 711-718.

3. Ochiai R, Jokura H, Suzuki A et al. (2004) Hypertens Res 27, 731-737.

4. Olthof MR, Hollman PC, Buijsman MN et al. (2003) J Nutr 133, 1806-1814. 